\title{
Infancy and Early Childhood Development in Children Raised by Foster Parents in Romania
}

\begin{abstract}
The first days, months and years in a child's life are crucial for his development. At first, the sensory processes are being developed, and the infant learns to examine his hands, to look at people who are moving in front of him and to squeeze another hand. This process is accompanied by the development of the thought processes and the emotions.

Children who are abandoned after birth spend a period of time being hospitalized, until Child Protection Services finds the best solution to protect the babies, which in most of the cases is the placement at a foster parent. This period of time has a major impact on the infant because of the absence of the mother and the child is not being properly stimulated. These children suffer an abandonment trauma, which causes negative psychological effects that influence the development: difficulty in forming a secure attachment, delay in cognitive development and in other areas of functioning, increased possibility of developing cognitive distortions. The role of a foster parent in the infant stage is of a high importance because he or she is the person to whom the child forms attachment, gives the child the opportunity of being raised in a family, to have models and become more resilient. Nevertheless, in the upbringing of children the effects of the abandonment trauma are still being seen in most of them: the child has low self-esteem, he forms an insecure attachment, develops signs of mental illness and difficulties in autonomy.

This paper is an immersion in the literature on the development of children who were abandoned after birth. The novelty of the theme is represented by the observations made on the upbringing of these children at foster parents in
\end{abstract}

1 General Directorate of Social Assistance and Child Protection, Bucharest, Romania, E-MAIL: cabinet.flaviateculeasa@gmail.com. 
Romania since the implementation of foster care in this country until the present day. There is a need to improve the training of the foster parents and the methods used by specialists in working with the children, so that they can become more resilient and have adequate coping mechanisms in the adult stage.

\section{Keywords:}

infant development, early childhood development, abandonment trauma, foster parents, foster care in Romania

\section{INTRODUCTION}

\section{PHASES AND STAGES IN THE HUMAN BEINGS' DEVELOPMENT}

In order for a human being to fully develop, two important life phases are needed to be crossed. We are talking about the prenatal and the postnatal phase. Each phase has its characteristics and its changes that establish how the human being is going to evolve. It is well known that from the moment the baby is conceived, until its birth, the fetus's development is highly influenced by the mother's behaviors, emotions and the events that are happening in her life during pregnancy. That is why different types of stress during pregnancy, such as disasters, life events, perceived stress, work stress and daily hassles, have been associated with different areas of child development, including birth outcomes, play, cognition, language, temperament, behavior and motor (Moss et al., 2017).

The reason why stress at a particular time during pregnancy can influence one area of development in the fetus and not another, is connected to the maturity of each system and each fetal organ that is reached at that particular time. For example, the stress exposure during the first and second trimester of pregnancy was associated with poorer cognitive development, whereas third trimester exposure was key for motor development (Cao, Laplante, Brunet, Ciampi, \& King, 2014). How the child develops when the fetus is exposed to prenatal maternal stress is also influenced by the sex of the fetus. Both animal and human studies show that male and female fetuses respond differently to prenatal adversity, laying the foundation for sexually dimorphic trajectories of development. It has been theorized that males are more vulnerable to developmental insults, including prenatal adversity, yet females experience increased variability in developmental trajectories (Sandman, Glynn, \& Davis, 2013).

During pregnancy, mothers who abandon their children experience adverse experiences and are prone to increased vulnerability. Mothers who abandon their children often have a difficult life: either they live in harsh conditions because of their financial difficulties, or they live with an abusive partner and have no support 
from their families. Many mothers who abandon their children were abandoned as well when they were infants. Moreover, in cases of abandonment, it has been observed that the mother has emotional or psychiatric problems, or she is abusing substances. In many cases, the mother hasn't attended elementary school and cannot read or write. The lack of education has a major impact on people, considering the fact that many women don't use birth control methods and they abandon not only the first child they give birth to, but some of the others too.

The postnatal phase is the longest and the most important phase for the psychological development of a human being. This phase, according to Crețu (2009), is divided in stages in which both physical and psychological transformations are being made. These stages are: 1 . infancy, between the moment of birth and 1 year; 2. the stage between infancy and preschool (1 year to 3 years), which is marked by independence in speech and movement; 3. the preschool stage (between 3 and 6 years), which is marked by consolidation of the processes and psychological structures and their constant voluntary and conscious progress; 4 . the school stage (between 6 and 10 years), in which the child cumulates information and basic skills through learning; 5 . the stage before adolescence (between 10 and 14 years); 6. the adolescence (between 14 and 19/20 years), in which the person is oriented towards searching for his/her self-identity; 7. the prolonged adolescence stage (between 20 and 24 years).

\section{INFANCY. THE DEVELOPMENT OF THE ATTACHMENT AND COGNITIVE FUNCTIONS}

One of the earliest, most intense, and most enduring experiences of childhood, the parent-child caregiving relationship appears to be a prime candidate to account for environmentally driven individual differences in children's brain development. As documented by longitudinal studies spanning infancy to early adulthood, by meta-analytic reviews and by experimental studies, the quality of caregiving relationships forecast child outcomes as diverse as social and emotional adjustment, moral development, cognitive functioning, sleep-wake cycles and sympathetic and parasympathetic response (Bernier, Calkins, \& Bell, 2016). Such pervasive effects on socioemotional, cognitive, and biological functioning are often believed to transit through children's neural circuitry (Belsky \& de Haan, 2011). The connection that is established between the mother and child determines the type of attachment that the child develops. The attachment can be evaluated by the specialists using the Strange Situation, which is a technique developed by Mary Ainsworth to observe the attachment style developed by the child.

Also, a large number of studies have linked parental characteristics to infant attachment, including parents' sensitive behavior toward the infant, state of mind 
with regard to the attachment, insightfulness, and reflective functioning (Smyke, Zeanah, Fox, Nelson, \& Guthrie, 2010). It is clear that a child can form a secure attachment if the parent is emotionally available for the child and if the parent has a good capacity of understanding and dealing with his/ her own emotions. The attachment formed by the child will influence his life, his choices and his ability of forming healthy relationships. In other circumstances, the child will form other type of attachment, such as the avoidant attachment, the ambivalent attachment and disorganized attachment. In the case of abandoned children, the ability to form a secure attachment can be severely affected because the child has lost his person of reference and the possibility to form a connection with the parent.

More than 50 years of literature on attachment theory has shown that early childhood experiences, especially parent-child relationships, influence how adults parent their own children. The transition to parenthood brings joys as well as significant challenges. Caring for an infant may be especially trying for parents who themselves had difficult childhoods, including abuse, neglect, and household dysfunctions (Steele et al., 2016).

Another aspect in the mother-child connection is breastfeeding. When the mother is breastfeeding the child, the connection between them is consolidated and the child is feeling more secure. The medical benefits of breastfeeding for both mother and child are considered numerous and well documented, but the effect of breastfeeding on general cognitive abilities has been a topic of debate for nearly a century (Girard, Doyle, \& Tremblay, 2017). The nutrients found in the breast milk have been implicated in both visual and neural development and functioning through neural maturation, which is important for cognitive abilities, such as problem solving. Also, it has been observed that deficiency of fatty acids, such as DHA, during lactation resulted in poor memory retention during learning tasks, whereas supplementation of DHA had reversal effects. In a study that hypothesized breastfeeding is associated with enhanced infant-mother attachment, 152 mothers were assessed by administration of questionnaires. Although the quality of the dyadic interaction in infancy, rather than feeding type, is predictive of attachment security, mothers who choose to breastfeed display enhanced sensitivity during early infancy, that in turn may foster secure attachment. Among the breastfeeding mothers, higher sensitivity is associated with longer duration of breastfeeding during first postpartum year (Britton, Britton, \& Gronwaldt, 2006). In most cases of abandoned children, they are being left in the hospital after their birth, or are brought in the hospital in the infancy stage, thereby being deprived of breast milk. Moreover, being in the hospital, they are in a situation of uncertainty, unable to form a secure attachment in relation to a person of reference. In the period of time 
in which they are being held in the hospital because of the fact that they cannot be properly stimulated, the infants can develop motor and cognitive delays.

At birth, infants exhibit a number of biases that preferentially orient them to socially relevant stimuli. In particular, it has been shown that newborns prefer faces over other kinds of visual stimuli, voices over other kinds of auditory stimuli, and biological motion over other kinds of motion (Grossmann, 2015). There is a real need for the infant to see and hear a representative person, such as the mother, as to feel safe and secure.

The ability to express emotions and distinguish others' emotions is an earlyoccurring, integral component of social development. Infants display and can imitate emotional expressions during the first year of life, with these behaviors having far-reaching implications across different domains of development. Differences of the expression of emotion are central to the constructs of temperament and attachment (Ghera et al., 2009). Expression of emotion also plays a critical role in the development of conscience and morality, and emotion identification is a cornerstone of social functioning and interaction (Herba \& Phillips, 2004).

\section{THE IMPACT OF ADVERSE CHILDHOOD EXPERIENCES ON PARENT-CHILD RELATIONSHIP}

Adverse childhood experiences (ACE) are operationally defined as childhood events, varying in severity and often chronic, occurring in a family or social environment and causing harm or distress. The literature provides various examples of ACE ranging from physical battering to failure to receive love and comfort. Examples of ACE include child sexual, physical and emotional abuse, as well as household dysfunctions, violent crime, unstable home life (many caregivers and relocations), poverty and family stress (Kalmakis \& Chandler, 2014).

Childhood adversity has been associated since 1900s with subsequent psychological and physical health problems, including developmental and emotional problems in children, health-risk behaviors among adolescents and a multitude of persistent, challenging psychological and physical illness among adults. Mothers who abandon their children are women who have suffered at least one adverse childhood experience, that made them incapable of being physically and emotionally available for their children. Unfortunately, by abandoning the children, they are exposing them to sever trauma and adverse childhood experiences, thereby a vicious circle being created. Some outcomes that were demonstrated to be associated with ACE and could impinge on parenting include depression, suicidality, risk of illicit drug use and HIV sexual risk behavior, alcohol abuse, heart disease, skeletal fractures, cancer, diabetes, and overall poorer health (Steele et al., 2016). 
Research on the impact of ACEs and attachment among adults may provide a better understanding of the mechanisms through which problematic parenting may occur. Using a 10-category Adverse Childhood Experiences Questionnaire (Murphy et al., 2014), it was found that mothers who reported four or more ACEs demonstrated significantly higher rates of unresolved loss or trauma or highly disparate states of mind in response to the Adult Attachment Interview, the gold standard measure of attachment patterns in adults. Interviews classified as unresolved and/or cannot classify show failures in reality testing, dissociation, absorption, rapid shifts in one's emotional stance, and numbing or passivity, and predict the most troubling infant-parent relationships, in which fear and disorganization predominate. In parents, these interview-based attachment classifications tend to be associated with higher rates of child maltreatment and more hostile intrusive behaviors (Lyons-Ruth \& Jacobvitz, 2008).

\section{EMOTIONAL AND COGNITIVE DEVELOPMENT IN EARLY CHILDHOOD}

In the early childhood, the development which started in the infancy stage, is now more organized and defined. The perception is getting more operative and better organized. The visual perception has a good functioning in the proximity of the child and with familiar objects. The symbolic play is now present in the child's activity, as a new capacity of the child to discover in an object with real characteristics, new functionalities and characteristics which are not real, but are given by the integration of the object in the play scenario. The capacity of memorization is unintentional and the child can memorize concrete aspects which are repetitive and are connected to the child's wishes and needs. The capacity of attention is also unintentional. It is superficial and strongly stimulated by what the child sees in the world and in the space he explores daily. According to Crețu (2009), the child at the age of 3 years has an expressive vocabulary of approximately 1000 words. The constant interaction that the child has with his objects and the communication with his mother represent the source of the word's semantic content, which the baby assimilates in the stage of early childhood.

One of the characteristics of the emotional development is the dominance of positive emotions, giving the fact that the child becomes more in touch and wellbalanced in relation to the environment. In this stage, the emotions are beginning to be influenced by memories or by the ability of anticipation. The child can realize if a certain place brought him joy or emotions of fear before and reacts in the present considering previous emotions. Moreover, the means that are used by the child to express his emotions are now enriched because the child is now imitating the adult. The attachment that the child forms towards the mother is getting even 
stronger because there is a permanent contact between them, they are communicating, the mother is showing constant affection towards the baby and is available when the child needs comfort.

Unfortunately, there are situations in which the mother abandons the child in the stage of the early childhood because they cannot deal with their financial, conjugal or emotional problems. In this case, the child forms memories about his mother and there is a history of a relationship between them. This is an event which has a major traumatic potential, considering the child's stage of development and the course of his life before his abandonment.

Another aspect concerning the emotional development is the development of self-regulation. Self-regulation is a complex, multicomponent construct operating across several levels of function (e.g., motor, psychological, socio-emotional, cognitive, behavioral and motivational) (Montroy, Bowles, Skibbe, McClelland, \& Morrison, 2016). It is a construct for which the development begins in infancy, with many of the skills that are important for behavioral self-regulation developing first as separate domains, and then becoming organized and integrated over time. For example, emotional self-regulation appears to develop before behavioral self-regulation.

Language is a child attribute that affects developing self-regulation, and this may be an important factor for understanding potential self-regulation trajectory differences across children. Theoretically, language is thought to give children "mental tools" to help them organize and modify their thoughts and behaviors. During early childhood, expressive language in particular may be important, as it enhances the ability of the child to both name their own current state and manipulate that state in relation to a specific context (Cole, Armstrong, \& Pemberton, 2010). Early expressive language skills are associated with higher levels of early self-regulation, with greater language gains across preschool and the transition to kindergarten associated with greater self-regulation gains (Bohlmann, Maier, \& Palacios, 2015). This suggests that children with higher levels of expressive language develop self-regulation faster compared with children with lower levels of language.

The children who are abandoned have delays in language acquisition because of several reasons: poor or lack of stimulation in the biological family, number of days spent in the hospital until a foster family can take them, the period of time the child had spent in an institution in the previous years. Considering this, they have poorly developed abilities of self-regulation and identifying some complex emotions. 
Past research consistently demonstrates that children's environments affect developing behavioral self-regulation. One particularly salient aspect of children's environments that may affect developing self-regulation is their mothers' education levels. Mother education often serves as a rough, yet important, proxy of family socioeconomic status and resources (Bradley \& Corwyn, 2002). Low maternal education levels have been linked to lower socioeconomic resources and higher stress levels that, over time, can affect children's developing neuroendocrine processes. Maternal education levels are also associated with distinct parenting profiles that include mothers' warmth, responsiveness, use of rich language inputs, and ability to maintain their children's attention (Montroy et al., 2016). Considering the fact that maternal education levels are linked to the mother's ability to show warmth and responsiveness to the child, they can be also linked to the abandonment of the children. Most mothers who abandon their children come from poor families and have little to no education.

A young child's developing brain is activated and patterned by the nurturing care of trusted adults. Nurturing interactions comprise attentive responses to young children's efforts to connect to and learn about their world, and involve efforts to present children with age-appropriate learning experiences in a safe and mutually enjoyable way. Nurturing care can break down under conditions of extreme poverty, family and societal conflict, discrimination, and other forms of individual and social stress (Daelmans et al., 2017).

\section{INSTITUTIONALIZATION OF CHILDREN}

Historically, institutions have been the most common form of care for orphaned and abandoned children throughout the world, and they are still a form of care for some of the abandoned children today. Because institutional rearing often involves social and even material deprivation, disturbances of growth, cognitive development, and language as well as greater levels of problem behaviors have been noted for more than 50 years among young children raised in institutions (Smyke et al., 2007). Institutionalized children are children who grow up in an institution, who were abandoned by their parents and who are being cared for by specialized personnel. One caregiver has to take care of more than one child. Institutionalization has been shown to have dramatic consequences for children's development across a variety of domains (Marshall, Fox, \& Group, 2004).

The idea of institutionalization has changed over the years, considering the fact that the children's development is being endangered, and it has been promoted the placement of the child, as soon as possible, at a foster family, if the biological 
family refuses to take care of the baby, or doesn’t have the financial support to do so.

Institutionalization of children in Romania. Institutional care, which has been the chief form of care for orphaned and abandoned children for more than 200 years in Romania, became even more widespread during the Communist era there from 1945 to 1989. Following the revolution of 1989, it became clear that tens of thousands of young children were living in institutions, most in appalling conditions (Smyke, Zeanah, Fox, \& Nelson, 2009). The orphanages, as they were called, were crowded and the children were not sufficiently stimulated because there were not enough caregivers for all the children. Adoption of thousands of these children into North America and Western European families was common for about 12 years. International adoptions had been suspended in the year 2000 because there were rumors that they were corrupt. But until then, Romania was the leading source of international adoptions for families in the United States and many other Western countries in the decade of the 1990s (Zeanah et al., 2003). Foster care was implemented on a small scale by international adoption agencies who placed some young children in foster homes for a few months before they were adopted out of the country. They had used the French model, in which designated foster parent was paid a salary and benefits for the job of being a foster parent, in contrast to the US system in which generally modest board payments follow the child in care wherever they are placed (Smyke et al., 2009).

At present, in Romania, the law that protects and promotes children's rights is called The Law 272/2004 and has been republished in 2014 and updated in 2015. In the republished version of the law it said that the child under 2 years old cannot be placed in a care centre. In the updated version from 2015 it is mentioned that the child under 3 years old cannot be placed in an institution, but only in the extensive family, at a foster family, or foster parent. The child under 3 years old can be placed in an institution only if he/she has a handicap that imposes professional care in a specialized institution. Moreover, an infant, after his birth, cannot be held for a long period of time in the maternity, and has to be taken over by the Child Protection Services in order to be placed at a foster parent. The number of institutions caring for children has dropped over time.

The Bucharest Early Intervention Project. The Bucharest Early Intervention Project is described as a scientific and humanitarian project designed to document the effects of institutionalization on the development of young children, to determine the degree of recovery from early adversity that foster care can provide, and to assist the government of Romania in building an infrastructure to support alternative forms of care beyond institutionalization for children in difficulty 
(Zeanah et al., 2003). The aim was to provide an affordable and culturally appropriate model of foster care that was informed by developmental science about the needs of young children (Tibu, Humphreys, Fox, Nelson, \& Zeanah, 2014).

The Bucharest Early Intervention Project (BEIP) is, to our knowledge, the first-ever randomized clinical trial of foster care as an intervention for early institutionalization. At approximately 2 years of age, 136 children who had spent more than half of their lives in institutions in Bucharest, Romania, were recruited for the study. The BEIP core group (involving principal investigators and original staff members of the study) performed randomization procedures, and each child was assigned to care as usual group, or to the foster care group (Bick et al., 2015). The feasibility phase of the study, conducted in Bucharest, Romania, began in November 2000, and the study itself began in April 2001. The total number of children who participated in this study was 208, and this number includes comparison children, recruited from local health centers, who had never been institutionalized and lived with their families in Bucharest. The range of age of the children when the study began was 5 to 30 months. BEIP personnel were Romanian psychologists and social workers who were recruited in Bucharest. The project manager was a Romanian-born American citizen who was particularly adept at understanding and addressing the cross-cultural issues that were inevitable with such an effort (Smyke et al., 2009).

Because government-sponsored foster care was limited to about one family when the BEIP commenced, the project created his own foster care programs. 56 foster families were recruited into the project, after screening. A total of $46 \%$ were single-parent families, and foster care mothers ranged in age from 30 to 66 years old; all mothers had at least a high school education (Nelson et al., 2007).

The BEIP is the first study to experimentally examine the physical, psychological, and neural sequelae of institutional rearing and the developmental trajectories of children removed and placed into a novel foster care intervention (Vanderwert, Zeanah, Fox, \& Nelson, 2016).

\section{FOSTER CARE}

A foster parent or foster carer in Romania is a person who is employed at the General Directorate of Social Assistance and Child Protection and receives a salary and benefits, in exchange of taking care of one or more children at his home. According to the Manual of the Foster Carer (Manualul Asistentului Maternal Profesionist) which was written in 2007 by the AGAPEDIA NGO, the foster carer has to be certified by the local Commission for Child Protection Services, in order to ensure the necessary education and care for the children who are received 
in placement. A foster parent can take care of up to 3 children, with or without disabilities. Foster parents are a wife and husband who are both taking care of children at their home, in exchange for a salary. But placement of an abandoned child can be made in the extended family, at a foster parent, or in an institution, depending on the child's age, health, and with respect towards the child's rights. This action is decided by the local Commission for Child Protection Services or by Romanian law. The child's opinion can be taken into consideration, when the law demands this.

The foster parents' network had been brought into existence towards the end of 1998. It had been implemented as an alternative to institutionalization, and it is a part of a process called "the deinstitutionalization movement." At first, they were part of the Bucharest Early Intervention Project, but after the suspension of international adoptions, foster parents were undertaken by the Child Protection Services. The number of foster parents began to decrease after 2010, when the government applied massive salary reductions in the budgetary sector. At present, the number of foster parents is still low because fewer and fewer people choose this occupation.

\section{THE OBJECTIVE OF THE PAPER}

The objective of this theoretical paper is to describe the development of children in the infancy and early childhood stage, when they are in the care of foster parents in Romania. The existing research on the present subject, information about the activity of foster parents and the writer's own observations on the development of children who are in the care of foster parents have been used for the completion of this paper. Also, comparisons have been made referring to the emotional and cognitive development of children being in the care of an institution and children being in the care of foster parents.

\section{METHODOLOGICAL ASSUMPTIONS \\ OF THE PRESENT RESEARCH/THEORETICAL PAPER}

\section{COGNITIVE DEVELOPMENT OF CHILDREN IN FOSTER CARE}

At the beginning of the BEIP, baseline assessments of physical development and growth, cognitive level, problem behaviors and competence, and emotional expression were obtained on participants from the children who were institution- 
alized and the children who were never institutionalized. The Bayley Scales of Infant Development II and the Mental Development Index (MDI) were used to assess developmental status. The Mental Development Index (MDI) scores for children being raised in institutions were markedly below those of never institutionalized children. For the institutionalized group of children, the MDI scaled scores declined as chronological age increased (Smyke et al., 2007).

It has to be mentioned that at the beginning of the BEIP, infants were still being placed in institutional care. One of the goals of the present study was to determine the contribution of the caregiving quality and how this influences the development of the children who had spent more than half of their life in institutions. With regard to the cognitive abilities, it has been found that observed caregiving quality was positively related to Developmental Quotient (DQ). As caregiving quality increased and percentage of the child's life spent in the institution decreased, DQ was higher, indicating that the caregiving quality was an important contributor to DQ (Smyke et al., 2007).

In another study conducted by Bick et al. (2015), the objective was to examine associations among neglect in early life, early intervention, and the microstructural integrity of white matter pathways in middle childhood. In this study, at approximately 8 years of age, 69 of the original 136 children from the BEIP underwent structural magnetic resonance imaging scans. Diffusion tensor imaging data from participants (aged 8-11 years) were selected for the tract-based spatial statistics analysis to investigate potential white matter abnormalities due to institutional rearing during early development. Results suggest that removal from conditions of neglect in early life entry into a high-quality family environment can support more normative trajectories of white matter growth (Bick et al., 2015).

In another study conducted on children originally placed in institutions who were assessed comprehensively and then randomized to foster care or care as usual, the researchers report on the brain electrical activity (electroencephalogram: EEG) on 12-year-old children. Previous report suggested improvement in resting EEG activity for the group children placed in the foster care intervention, particularly those placed before 24 months of age compared to children who were randomized to care as usual (institutional care) or those placed into families after this age (Vanderwert et al., 2016). The findings highlight the importance of maintaining a stable high quality caregiving environment, particularly for children exposed to early psychosocial deprivation, for promoting healthy brain development.

The principal investigators of the Bucharest Early Intervention Project, Nathan A. Fox, Charles Nelson, and Charles H. Zeanah, have taken an interest in the research on children who have been exposed to institutionalized care after their 
birth and on the benefits of placing the children at foster parents. The research has included the cognitive development of the children, including aspects concerning the children's brain functioning, the Developmental Quotient, and language development. Children's language after institutional care has begun to receive particular attention, in part because language is a key marker of academic and social competence. While children in both institutional and foster care continued to learn language from 30 to 42 months, the more typical environment of foster care affected language development in a profoundly positive way. Timing of foster placement was critical. Children placed in foster care by 24 months showed very improved language outcomes at 30 and 42 months. Children placed later had strikingly severe expressive and receptive delays, equal to those of children in institutional care (Windsor, Glaze, \& Koga, 2007).

\section{EMOTIONAL DEVELOPMENT OF THE CHILD PLACED IN FOSTER CARE}

The type or quality of attachments a young child forms seems to reflect neural processes that are "experience dependent." That is, attachment theory posits that the young child constructs attachment relationships that reflect the child's experiences with particular caregivers. As a child forms an attachment to an adult caregiver, experiences with that adult seem to relate to the type or quality of that attachment (Smyke et al., 2010).

To determine whether signs of disordered attachment were greater in young children being reared in more socially depriving caregiving environments, three groups of children were studied by means of structured interview with caregivers that were administered over several months in Bucharest, Romania, in 1999. The sample was represented by a group of toddlers living in a typical unit in a large institution in Bucharest, a group of toddlers living in the same institution on a "pilot unit" designed to reduce the number of adults caring for each child, and a group of toddlers living at home, who had never been institutionalized. The results were that children on the typical unit (standard care) had significantly more signs of disordered attachment than children in the other two groups. Both the emotionally withdrawn and the indiscriminately social pattern of attachment disorder were apparent in these children (Smyke, Dumitrescu, \& Zeanah, 2002).

Placing the child at a foster carer enhances the chance that the child will develop a secure attachment because in the infancy and early childhood stage, he interacts predominantly with the foster parent. Infants raised in institutions have far more limited opportunities to develop selective attachments than infants raised in more normative environments because the caregivers in these institutions perform shift-work, and because they usually are responsible for the care of 
many young children. Moreover, the emotional investment in the children they care is limited.

In the largest and most comprehensively study of attachment conducted to date in institutionalized children, findings about signs of Reactive Attachment Disorder in this sample were amplified by assessments of attachment from the developmental perspective using the Strange Situation Procedure (Zeanah, Smyke, Koga, Carlson, \& BEIP Core Group, 2005). In another study that was elaborated in 2012, the researchers determined whether the ameliorative effect of a foster care intervention on internalizing disorders in previously institutionalized children was explained by the development of secure attachment among children placed in foster care. Placement into foster care facilitated the development of secure attachment and prevented the onset of internalizing disorders in institutionalized girls. The differential effects of foster care on attachment security in boys and girls explained gender differences in the intervention effects on psychopathology. Findings provide evidence for the critical role of disrupted attachment in the etiology of internalizing disorders in children exposed to institutionalization (McLaughlin, Zeanah, Fox, \& Nelson, 2012).

According to Smyke et al. (2010), children placed in foster care before 24 months were more likely to have secure attachments and if placed earlier were less likely to have disorganized or insecure-other attachments. Cognitive status predicted greater likelihood of organized attachment in the institutionalized children and greater likelihood of secure attachment in the foster care and never-institutionalized groups. Foster care is an important intervention to reduce the adverse effects following early deprivation.

Through the Bucharest Early Intervention Project, institutionalized and foster care children, along with a community-based comparison group, were evaluated on emotion tasks at 30 and 42 months of age. Behaviors reflecting positive and negative affect and attention were coded from videotapes. Data indicated that at both age points, children who received the foster care intervention showed higher levels of attention and positive affect compared to children who remained institutionalized. Compared to the community sample, children in the foster care intervention showed higher levels of attention to the emotion-eliciting tasks at 42 months of age (Ghera et al., 2009).

In the period of time prior the suspension of international adoptions, children from Romania had been adopted in countries like Canada, the UK, etc. It has been shown that, as an effect of early institutionalization, children displayed internalizing problems and difficulty coping with social interactions, and they often scored highly on parent report of indiscriminate "friendly" behavior (Chisholm, Carter, 
Ames, \& Morison, 1995). Nevertheless, being in a family, having the opportunity to form healthy attachments, and to benefit from a mother-figure and a father-figure, represents a chance for adopted children to grow up and become healthy and well-integrated adults.

In a study performed by Țibu et al. (2014), the aim was to explore potential differences in psychiatric symptoms in children placed in different types of foster care. Internalizing disorders (major depressive disorder, generalized anxiety disorder, posttraumatic stress disorder, etc.), externalizing disorders, such as oppositional defiant disorder, conduct disorder, etc., and attention deficit hyperactivity disorder (ADHD) were assessed in 54-month-old children living with foster families. One group of children living in high-quality foster-families who had benefited from specialized training and support from the BEIP, and another group of children placed with government-sponsored foster care (GSFC) in Bucharest, Romania were compared. The government-sponsored foster care did not exist when the Bucharest Early Intervention Project began. The results show that girls included in the foster care program of the BEIP had fewer signs of internalizing disorders and ADHD compared to those in GSFC, whereas boys were roughly similar in all symptoms domains between groups. Girls' reduced symptomatology was mediated by security of attachment to their foster mothers (Tibu et al., 2014).

\section{DISCUSSION}

At present, even though abandoned children by 36 months are placed to a foster parent as soon as possible, some of the children experience cognitive delays, expressive and receptive language delays, accompanied by motor delays in infancy and later difficulties in motor tasks. The ideal situation is that the abandoned child is placed immediately after his birth at a foster parent. Even so, there are other factors that must be taken into consideration, like: events that happened in the prenatal phase, the current state of health of the mother (including physical diagnoses, psychiatric illness, if she is a drug consumer, etc.). The moment when the abandoned child is placed at a foster carer is crucial, and any delay in this process can represent difficulties in the child's development.

Lately it has been observed that a considerable number of children placed at foster carers have psychiatric diagnoses. Most of them are diagnosed with hyperkinetic disorder and have cognitive delays. Regarding the emotional development, many children were able to form a secure attachment, but there are other children who manifest an anxious-ambivalent attachment. They cannot separate from the 
foster parent, and they don't feel reassured when the caregiver returns to the child. On the other hand, there are children who present symptoms of the disinhibited attachment disorder, which means that they approach and interact with unfamiliar adults. This is a dangerous behavior because the child can leave with a stranger, not being aware of the consequences.

Being in the care of a foster parent, the child can benefit from a mother-figure and a father-figure and can grow up with the idea of a family. Foster parents are often called mothers or fathers. The benefits of placing a child at foster parents are enormous. The child has an opportunity of a good start in life, in order to reach his highest potential. Being placed at a sensitive, emphatic and self-aware foster parent, the child can become emotionally balanced and form a healthy personality. The placement of the child at a foster parent is a temporary action, and the purpose of the Child Protection Services is to act in the best interest of the child, whether this means to reunite the child with his family, or to proceed with the adoption endeavors. There are situations in which neither the reunion with the family, nor the adoption endeavors are possible, and the child remains in foster care until he is 18 years old. In this case, the child becomes part of the foster family, and many families decide to proceed with another form of placement, which is placement in a family (the child benefits from a monthly allowance and the foster parents are no longer state employees).

However, being a foster parent in Romania is not a well-paid occupation, and the person who is employed as a foster carer cannot have another job. The law makes it difficult for these people to have vacations, with or without the child they care for, and determines the foster carers to explain and demonstrate every action that involves the child. Moreover, the law which allows pensioners to continue to be foster parents has become more limitative since 2013.

\section{CONCLUSIONS, IMPLICATIONS AND FUTURE WORK}

After the children who were involved in the Bucharest Early Intervention Project turned 54 months of age, arrangements have been made for the foster care network that had been supported by the project to be transferred by the local governmental sectors in Bucharest. Because Romania was undergoing a transition from institutional care to foster care at that time, the local governments hired the foster parents and used governmental social workers to monitor the needs of these families (Smyke et al., 2009). Currently, all foster parents are still state employees. 
The number of foster parents is not sufficient for the number of children who are in need for care.

The low level of education and poverty in some areas of the country, the large share of work-age population depending on social assistance benefits and relatively weak education outcomes of school-aged children living in poor or vulnerable households, the continuous social exclusion are factors that contribute to the fact that Romania is still struggling with the problem of child abandonment. Other factors such as the inability of the mother to emotionally invest in her child, adverse childhood experiences of the mother and father, poor mental health, and other family difficulties have a considerable impact on this issue.

The work of a foster carer has an immense importance for the community. Because of foster parents, children who are in their care can grow up with a strong identity, a healthy personality and can become well-balanced people who can be easily integrated in the community. Moreover, foster parents are representative people for the children in their care and can positively influence the emotional development of the children. The help of social assistants and psychologist is crucial for the best interest of the children and the foster parents.

But in order for foster parents to be a positive model for the children and to properly invest in their upbringing, they have to receive more support from the government, and from Child Protection Services. Besides counselling which is offered by psychologists from Child Protection Services, setting up support groups, having continuous opportunities to learn about the best parenting skills are aspects of great importance for both the foster parent, and the child. Foster parents should be able to benefit from paid vacations in which they can leave the child in the care of the extensive family of the foster parent, or in the care of another foster parent. At present, it is very difficult for foster carers to have vacations without the child they are caring for.

Further research on foster caring in Romania is necessary in order to raise awareness about foster parents' needs and how to improve the care of abandoned children in a substitute family.

\section{References:}

Belsky, J., \& de Haan, M. (2011). Annual Research Review: Parenting and Children's Brain Development: The End of the Beginning, Journal of Child Psychology and Psychiatry, 52(4), pp. 409-428. Retrieved from: https://doi.org/10.1111/j.1469-7610.2010.02281.x

Bernier, A., Calkins, S.D., \& Bell, M.A. (2016). Longitudinal Associations Between the Quality of Mother-Infant Interactions and Brain Development Across Infancy, Child Development, 87(4), pp. 1159-1174. Retrieved from: https://doi.org/10.1111/cdev.12518 
Bick, J., Zhu, T., Stamoulis, C., Fox, N.A., Zeanah, C., \& Nelson, C.A. (2015). Effect of Early Institutionalization and Foster Care on Long-term White Matter Development: A Randomized Clinical Trial, JAMA Pediatrics, 169(3), pp. 211-219. Retrieved from: https://doi. org/10.1001/jamapediatrics.2014.3212

Bohlmann, N.L., Maier, M.F., \& Palacios, N. (2015). Bidirectionality in Self-Regulation and Expressive Vocabulary: Comparisons Between Monolingual and Dual Language Learners in Preschool, Child Development, 86(4), pp. 1094-1111. Retrieved from: https://doi. org/10.1111/cdev.12375

Bradley, R.H., \& Corwyn, R.F. (2002). Socioeconomic Status and Child Development, Annual Review of Psychology, 53(1), pp. 371-399. Retrieved from: https://doi.org/10.1146/annurev. psych.53.100901.135233

Britton, J.R., Britton, H.L., \& Gronwaldt, V. (2006). Breastfeeding, Sensitivity, and Attachment, Pediatrics, 118(5), e1436-1443. Retrieved from: https://doi.org/10.1542/peds. 2005-2916

Cao, X., Laplante, D.P., Brunet, A., Ciampi, A., \& King, S. (2014). Prenatal Maternal Stress Affects Motor Function in 51/2-year-old Children: Project Ice Storm, Developmental Psychobiology, 56(1), pp. 117-125. Retrieved from: https://doi.org/10.1002/dev.21085

Chisholm, K., Carter, M.C., Ames, E.W., \& Morison, S.J. (1995). Attachment Security and Indiscriminately Friendly Behavior in Children Adopted from Romanian Orphanages, Development and Psychopathology, 7(2), pp. 283-294. Retrieved from: https://doi.org/10. 1017/S0954579400006507

Cole, P.M., Armstrong, L.M., \& Pemberton, C.K. (2010). The Role of Language in the Development of Emotion Regulation. In: S.D. Calkins \& M.A. Bell (Eds.), Human Brain Development. Child Development at the Intersection of Emotion and Cognition (pp. 59-77). Retrieved from: http://dx.doi.org/10.1037/12059-004

Crețu, T. (2009). Psihologia vârstelor. Iași: Polirom.

Daelmans, B., Darmstadt, G.L., Lombardi, J., Black, M.M., Britto, P.R., Lye, S., ... \& Richter, L.M. (2017). Early Childhood Development: The Foundation of Sustainable Development, The Lancet, 389(10064), pp. 9-11. Retrieved from: https://doi.org/10.1016/S01406736(16)31659-2

Ghera, M.M., Marshall, P.J., Fox, N.A., Zeanah, C.H., Nelson, C.A., Smyke, A.T., \& Guthrie, D. (2009). The Effects of Foster Care Intervention on Socially Deprived Institutionalized Children's Attention and Positive Affect: Results from the BEIP Study, Journal of Child Psychology and Psychiatry, 50(3), pp. 246-253. Retrieved from: https://doi.org/10.1111/ j.1469-7610.2008.01954.x

Girard, L.-C., Doyle, O., \& Tremblay, R.E. (2017). Breastfeeding, Cognitive and Noncognitive Development in Early Childhood: A Population Study, Pediatrics, 139(4), pp. 1-9. Retrieved from: https://doi.org/10.1542/peds.2016-1848

Grossmann, T. (2015). The Development of Social Brain Functions in Infancy, Psychological Bulletin, 141(6), pp. 1266-1287. Retrieved from: https://doi.org/10.1037/bul0000002

Herba, C., \& Phillips, M. (2004). Annotation: Development of Facial Expression Recognition from Childhood to Adolescence: Behavioural and Neurological Perspectives, Journal of Child Psychology and Psychiatry, 45(7), pp. 1185-1198. Retrieved from: https://doi. org/10.1111/j.1469-7610.2004.00316.x 
Kalmakis, K.A., \& Chandler, G.E. (2014). Adverse Childhood Experiences: Towards a Clear Conceptual Meaning, Journal of Advanced Nursing, 70(7), pp. 1489-1501. Retrieved from: https://doi.org/10.1111/jan.12329

Lyons-Ruth, K., \& Jacobvitz, D. (2008). Attachment Disorganization: Genetic Factors, Parenting Contexts and Developmental Transformations from Infancy to Adulthood. In: J. Cassidy, \& P.R. Shaver (Eds.), Handbook of Attachment (2nd ed., pp. 666-697). New York: Guilford Press.

Marshall, P.J., Fox, N.A., \& BEIP Core Group. (2004). A Comparison of the Electroencephalogram Between Institutionalized and Community Children in Romania, Journal of Cognitive Neuroscience, 16(8), pp. 1327-1338. Retrieved from: https://doi.org/10.1162/ 0898929042304723

McLaughlin, K.A., Zeanah, C.H., Fox, N.A., \& Nelson, C.A. (2012). Attachment Security as a Mechanism Linking Foster Care Placement to Improved Mental Health Outcomes in Previously Institutionalized Children, Journal of Child Psychology and Psychiatry, 53(1), pp. 46-55. Retrieved from: https://doi.org/10.1111/j.1469-7610.2011.02437.x

Montroy, J.J., Bowles, R.P., Skibbe, L.E., McClelland, M.M., \& Morrison, F.J. (2016). The Development of Self-regulation Across Early Childhood, Developmental Psychology, 52(11), pp. 1744-1762. Retrieved from: https://doi.org/10.1037/dev0000159

Moss, K.M., Simcock, G., Cobham, V., Kildea, S., Elgbeili, G., Laplante, D.P., \& King, S. (2017). A Potential Psychological Mechanism Linking Disaster-related Prenatal Maternal Stress with Child Cognitive and Motor Development at 16 Months: The QF2011 Queensland Flood Study, Developmental Psychology, 53(4), pp. 629-641. Retrieved from: https://doi. org/10.1037/dev0000272

Murphy, A., Steele, M., Dube, S.R., Bate, J., Bonuck, K., Meissner, P., ... \& Steele, H. (2014). Adverse Childhood Experiences (ACEs) Questionnaire and Adult Attachment Interview (AAI): Implications for Parent Child Relationships, Child Abuse \& Neglect, 38(2), pp. 224-233. Retrieved from: https://doi.org/10.1016/j.chiabu.2013.09.004

Nelson, C.A., Zeanah, C.H., Fox, N.A., Marshall, P.J., Smyke, A.T., \& Guthrie, D. (2007). Cognitive Recovery in Socially Deprived Young Children: The Bucharest Early Intervention Project, Science, 318(5858), pp. 1937-1940. Retrieved from: https://doi.org/10.1126/science.1143921

Sandman, C.A., Glynn, L.M., \& Davis, E.P. (2013). Is There a Viability-Vulnerability Tradeoff? Sex Differences in Fetal Programming, Journal of Psychosomatic Research, 75(4), pp. 327-335. Retrieved from: https://doi.org/10.1016/j.jpsychores.2013.07.009

Smyke, A.T., Dumitrescu, A., \& Zeanah, C.H. (2002). Attachment Disturbances in Young Children. I: The Continuum of Caretaking Casualty, Journal of the American Academy of Child \& Adolescent Psychiatry, 41(8), pp. 972-982. Retrieved from: https://doi. org/10.1097/00004583-200208000-00016

Smyke, A.T., Koga, S.F., Johnson, D.E., Fox, N.A., Marshall, P.J., Nelson, C.A., ... \& BEIP Core Group. (2007). The Caregiving Context in Institution-reared and Family-reared Infants and Toddlers in Romania, Journal of Child Psychology and Psychiatry, 48(2), pp. 210-218. Retrieved from: https://doi.org/10.1111/j.1469-7610.2006.01694.x

Smyke, A.T., Zeanah, C.H., Jr., Fox, N.A., \& Nelson, C.A., III. (2009). A New Model of Foster Care for Young Children: The Bucharest Early Intervention Project, Child and Adolescent Psychiatric Clinics, 18(3), pp. 721-734. Retrieved from: https://doi.org/10.1016/ j.chc.2009.03.003 
Smyke, A.T., Zeanah, C.H., Fox, N.A., Nelson, C.A., \& Guthrie, D. (2010). Placement in Foster Care Enhances Quality of Attachment Among Young Institutionalized Children, Child Development, 81(1), pp. 212-223. Retrieved from: https://doi.org/10.1111/j.14678624.2009.01390.x

Steele, H., Bate, J., Steele, M., Dube, S.R., Danskin, K., Knafo, H., ... \& Murphy, A. (2016). Adverse Childhood Experiences, Poverty, and Parenting Stress, Canadian Journal of Behavioural Science/Revue canadienne des sciences du comportement, 48(1), pp. 32-38.

Tibu, F., Humphreys, K., Fox, N.A., Nelson, C.A., \& Zeanah, C.H. (2014). Psychopathology in Young Children in Two Types of Foster Care Following Institutional Rearing, Infant Mental Health Journal, 35(2), pp. 123-131. Retrieved from: https://doi.org/10.1002/ imhj. 21428

Vanderwert, R.E., Zeanah, C.H., Fox, N.A., \& Nelson, C.A. (2016). Normalization of EEG Activity Among Previously Institutionalized Children Placed into Foster Care: A 12-year Follow-up of the Bucharest Early Intervention Project, Developmental Cognitive Neuroscience, 17, pp. 68-75. Retrieved from: https://doi.org/10.1016/j.dcn.2015.12.004

Windsor, J., Glaze, L.E., \& Koga, S.F. (2007). Language Acquisition with Limited Input: Romanian Institution and Foster Care, Journal of Speech, Language, and Hearing Research, 50(5), pp. 1365-1381. Retrieved from: https://doi.org/10.1044/1092-4388(2007/095)

Zeanah, C.H., Nelson, C.A., Fox, N.A., Smyke, A.T., Marshall, P., Parker, S.W., \& Koga, S. (2003). Designing Research to Study the Effects of Institutionalization on Brain and Behavioral Development: The Bucharest Early Intervention Project, Development and Psychopathology, 15(4), pp. 885-907. Retrieved from: https://doi.org/10.1017/S0954 579403000452

Zeanah, C.H., Smyke, A.T., Koga, S.F., Carlson, E., \& BEIP Core Group. (2005). Attachment in Institutionalized and Community Children in Romania, Child Development, 76(5), pp. 1015-1028. Retrieved from: https://doi.org/10.1111/j.1467-8624.2005.00894.x 